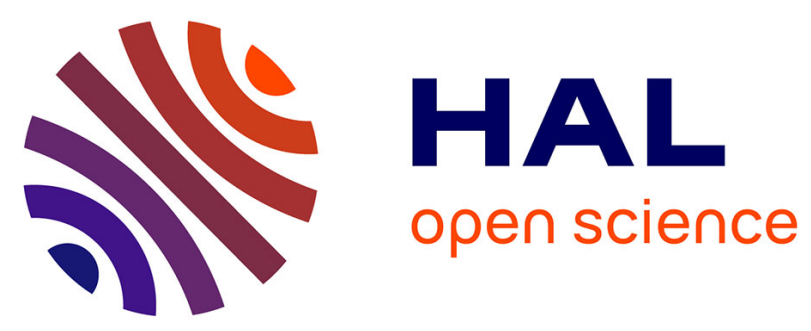

\title{
Improved 3D Imaging of Zebrafish Larvae Microcirculation by Digital Holography
} Alexey Brodoline, Nitin Rawat, Daniel Alexandre, Michel Gross

\section{To cite this version:}

Alexey Brodoline, Nitin Rawat, Daniel Alexandre, Michel Gross. Improved 3D Imaging of Zebrafish Larvae Microcirculation by Digital Holography. Digital Holography and Three-Dimensional Imaging, OSA, Jun 2018, Orlando, United States. pp.DW5F.5, 10.1364/DH.2018.DW5F.5 . hal-01922219

\section{HAL Id: hal-01922219 \\ https://hal.science/hal-01922219}

Submitted on 14 Nov 2018

HAL is a multi-disciplinary open access archive for the deposit and dissemination of scientific research documents, whether they are published or not. The documents may come from teaching and research institutions in France or abroad, or from public or private research centers.
L'archive ouverte pluridisciplinaire HAL, est destinée au dépôt et à la diffusion de documents scientifiques de niveau recherche, publiés ou non, émanant des établissements d'enseignement et de recherche français ou étrangers, des laboratoires publics ou privés. 


\title{
Improved 3D Imaging of Zebrafish Larvae Microcirculation by Digital Holography
}

\author{
Alexey Brodoline, Nitin Rawat, Daniel Alexandre, Michel Gross \\ Laboratoire Charles Coulomb, Université de Montpellier, Campus Triolet, Place Eugène Bataillon, 34095 \\ Montpellier cedex 5, France \\ alexey.brodoline@umontpellier.fr
}

\begin{abstract}
A microscopic technique based on digital holography is proposed to investigate blood microcirculation and vascular development in model organisms such as zebrafish larvae. Recent achievements in 3D imaging of blood flow in vessels are presented.

OCIS codes: (090.1995) Digital holography; (170.0180) Microscopy; (170.1470) Blood or tissue constituent monitoring; (290.5850) Scattering, particles.
\end{abstract}

\section{Citation}

A. Brodoline, N. Rawat, D. Alexandre, and M. Gross, "Improved 3D Imaging of Zebrafish Larvae Microcirculation by Digital Holography," in Imaging and Applied Optics 2018 (3D, AO, AIO, COSI, DH, IS, LACSEA, LS\&C, MATH, pcAOP), OSA Technical Digest (Optical Society of America, 2018), paper DW5F.5.

\section{Introduction}

Blood flow imaging is important for biological and medical purposes. It enables to assess physiological or pathological processes such as angiogenesis or tumor vascularization [1] and allows early detection of diseases [2] like age-related macular degeneration [3]. Since vascular systems are generally tridimensional structures, 3D visualization of microcirculation is of a great interest.

The presented label-free method, based on digital holography, generates 3D images of moving red blood cells (RBCs) in the vascular microsystem. The technique is validated in the case of a zebrafish larva (2-5 days of development). Compared to previous results [4,5], a better z-resolution is achieved here due to the use of a higher numerical aperture (NA) microscope objective.

\section{Materials and methods}

The experimental setup is similar to the one used in previous works [5,6]. It's a modified upright microscope (Olympus® CX41) where the illumination light source is replaced by a laser diode (HL6545MG: $60 \mathrm{~mW} \lambda=660 \mathrm{~nm}$ ) attenuated to not saturate the camera. The sample is a zebrafish larva (Danio rerio) of 2-5 days exposed to tricaine and fixed in agarose in a petri dish. The observation is performed with a Zeiss $®$ (x20/0.5 NA) water immersion microscope objective (MO). $G=41.2$ is the overall magnification of the setup.

The optical field scattered by the sample is collected by the MO and is combined with a coherent reference beam on the camera sensor (Mikrotron Eosens CL: 1280x1024 pixels, 14 $\mu \mathrm{m}$ square pitch, $200 \mathrm{~Hz}, 10 \mathrm{bits}$ ). The beam splitter that recombines the scattered $\left(E_{S}\right)$ and reference $\left(E_{R}\right)$ fields is angularly tilted to achieve off-axis holography. An interference pattern (the hologram) is produced at the sensor plane. The camera records the corresponding intensity $I_{C A M}(x, y)=\left|E_{R}+E_{S}\right|^{2}$. In order to eliminate the light scattered by the immobile objects and keep only the moving RBCs, the hologram $H_{C A M}$ is calculated by:

$$
H_{C A M}(x, y)=\sum_{n=1}^{6} I_{C A M, n}(x, y) \sin \left(n \frac{\pi}{3}\right)
$$

Where $I_{C A M, n}$ with $n=1 . .6$ are successive camera frames.

The optical field can be numerically back propagated from the sensor and reconstructed in a plane near the object. $E_{S}(x, y, z)$ can then be computed on either side of the sample plane using the reconstruction method described in [7]. A cube of data containing $E_{S}(x, y, z)$ is thus obtained, giving the complex field in a volume around the object. From this cube of data, the positions of the red blood cells (RBCs) are extracted using a cleaning algorithm. The reconstruction procedure and the cleaning algorithm are detailed in $[5,7]$. 


\section{Results}

The cleaning algorithm determines the positions of the RBCs in a grid of 640x640x128 pixels with pitches $\Delta x=\Delta y=$ $0.54 \mu \mathrm{m}$ and $\Delta z=1.08 \mu \mathrm{m}$. Note that the optical lateral resolution is smaller. The nominal resolution of the MO is $r=0.6 \lambda / O N=0.79 \mu m$. The calculations are made on a Nvidia GTX TITAN Graphics Processing Unit (GPU) using CUDA.

The results of the reconstruction are presented in Fig.1. It was made on 400 successive frames recorded at $200 \mathrm{~Hz}$. The averaging of the RBCs positions on 100 images gives the form of the blood vessels. The internal structure of the vascular system can be visualized. The rendering is performed using the OpenGL interface of Nvidia CUDA, which allows a convenient translation and rotation of the 3D image.

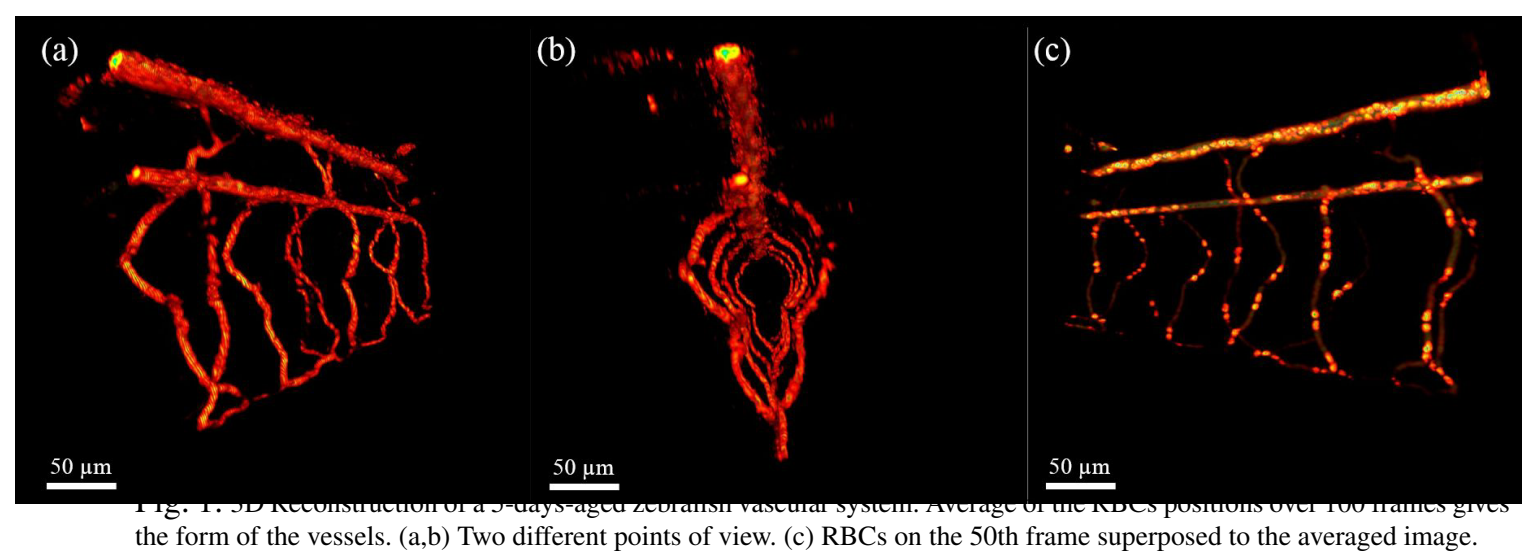

\section{Conclusion}

As compared with previous results, an improved 3D imaging is obtained. The use of a higher NA objective and the CUDA-OpenGL rendering enables a complete rotation around the object. The technique can be adapted to any microscope and can be combined with other conventional microscopic techniques, providing new tools for blood flow studies.

\section{Acknowledgements}

We acknowledge Labex Numev (convention ANR-10-LABX-20) for funding.

\section{References}

1. P. Carmeliet, and J. K. Rakesh, "Angiogenesis in cancer and other diseases," Nature 407,249-257 (2000).

2. M. P. Pase, N. A. Grima, C. K. Stough, A. Scholey, and A. Pipingas, "Cardiovascular disease risk and cerebral blood flow velocity," Stroke 43, 2803-2805 (2012).

3. E. Friedman, S. Krupsky, A. Lane, S. Oak, E. Friedman, K. Egan, and E. Gragoudas, "Ocular blood flow velocity in age-related macular degeneration," Ophthalmology 102, 640-646 (1995).

4. A. Brodoline, D. Donnarumma, D. Alexandre, and M. Gross, ”4D Holographic Reconstruction of Embryonic Blood Flow by Greedy Algorithm," in Imaging and Applied Optics 2016, OSA Technical Digest (Optical Society of America, 2016)

5. D. Donnarumma, A. Brodoline, D. Alexandre, and M. Gross, “4D holographic microscopy of zebrafish larvae microcirculation,” Opt. Exp. 24, 26887-26900 (2016).

6. D. Donnarumma, A. Brodoline, D. Alexandre, and M. Gross, "Blood flow imaging in zebrafish by laser doppler digital holography," Microsc. Res. Tech. (2016).

7. N. Verrier, D. Alexandre, G. Tessier, and M. Gross, "Holographic microscopy reconstruction in both object and image half-spaces with an undistorted three-dimensional grid," Appl. Opt. 54, 4672-4677 (2015). 